\title{
New Onset Atrial Fibrillation in Critically III Patients
}

\author{
M. E. Sleeswijk ${ }^{1}$, T. van Noord ${ }^{2}$ and J. G. Zijlstra ${ }^{3}$ \\ ${ }^{1}$ Flevoziekenhuis, Almere / Department of Critical Care, \\ ${ }^{2}$ Scheperziekenhuis, Emmen / Department of Critical Care, \\ ${ }_{3}^{3}$ University Medical Center Groningen, \\ University of Groningen / Department of Critical Care, \\ The Netherlands
}

\section{Introduction}

New onset atrial fibrillation is the most common rhythm disturbance in critically ill patients. Although it is frequently seen in critically ill patients, data regarding the aetiology and treatment are scarce. Extrapolating treatment regimes from non-critically ill patients is not recommended since there is a difference in aetiology of the arrhythmia. In this chapter we will discuss the pathophysiology and treatment strategies of new onset atrial fibrillation in medical- and non-cardiac surgery critically ill patients, based on the latest available evidence.

\section{Pathophysiology}

In critically ill patients the underlying mechanism for developing atrial fibrillation might differ from the outpatients clinic. Electrolyte disorders, rapid fluid changes like bleeding on one site and fluid overload by rapid filling in case of sepsis on the other site are present in excess and perfect triggers that induce atrial fibrillation. Reduced left ventricular function is also associated with atrial fibrillation. In critically ill patients, especially patients with sepsis, myocardial depression can occur, therefore inducing heart failure and, as a consequence, a higher risk of atrial fibrillation. Also underlying cardiac ischemia, for example the results of tremendous physically exercise which sepsis is, but also as a results of previously known or unknown coronary artery disease, can induce atrial fibrillation.

Recent studies have shown that elevated inflammatory biomarkers are associated with the development of atrial fibrillation. Inflammatory markers like C-reactive protein (CRP), highsensitivity CRP (hs-CRP) an interleukin-6 are elevated in both patients with paroxysmal as persistent atrial fibrillation (Chung et al 2001 Dernellis et al 2001, Gaudino et al 2003). Atrial fibrillation is also common in septic patients, (Salman et al 2008, Christians et al 2008) the incidence is even higher in patients with septic shock. $46 \%$ of patients with septic shock developed new onset atrial fibrillation, often with an increase in C-reactive protein (CRP) levels before the onset of atrial fibrillation. (Meierhenrich et al 2010) As most critically ill patients have elevated inflammatory markers, they, therefore might be at risk for the development of atrial fibrillation (Sequin et al 2006). Furthermore, atrial fibrillation is also associated with local inflammation like pericarditis and myocarditis. 


\section{Treatment}

Evidence for the best treatment strategy in critically ill patients is scarce. There are only 4 randomized controlled trials and furthermore 3 prospective follow-up studies who included mainly non-cardiac surgery and medical critically ill patients (table 1). However, since there is heterogeneity in not only patient selection, but also type of atrial arrhythmia and definition of treatment goals, these trials are not comparable and therefore the best treatment strategy based on these trials cannot be recommended. Even the question whether to treat or not critically ill patients with new onset atrial fibrillation has not been answered yet. Placebo controlled trials are lacking and, furthermore, spontaneous conversion is common in new onset atrial fibrillation, even in the setting of critically ill patients.

\begin{tabular}{|l|l|l|l|}
\hline RCT trials & $\begin{array}{l}\text { Number } \\
\text { of patients }\end{array}$ & Rhythm & Intervention \\
\hline $\begin{array}{l}\text { Chapman } \\
1993\end{array}$ & 24 & AT & Amiodarone vs Procainamide \\
\hline $\begin{array}{l}\text { Barranco } \\
1994\end{array}$ & 30 & SVT & Flecainide vs Verapamil \\
\hline $\begin{array}{l}\text { Moran } \\
1995\end{array}$ & 42 & SVT & Magnesium vs Amiodarone \\
\hline $\begin{array}{l}\text { Balser } \\
1998\end{array}$ & 64 & SVT & Esmolol vs Diltiazem \\
\hline Prospective & 10 & SVT & Amiodarone \\
\hline $\begin{array}{l}\text { Holt } \\
1989\end{array}$ & 37 & SVT & Direct current cardioversion \\
\hline $\begin{array}{l}\text { Mayr } \\
2003\end{array}$ & 29 & NAF & $\begin{array}{l}\text { Magnesium } \\
\text { Amiodarone }\end{array}$ \\
\hline $\begin{array}{l}\text { Sleeswijk } \\
2008\end{array}$ & &
\end{tabular}

$\mathrm{AT}=$ atrial tachycardia

SVT= supraventricular tachycardia

PSVT $=$ paroxysmal atrioventricular nodal reentrant tachycardia

$\mathrm{NAF}=$ new onset atrial fibrillation

A.fib $=$ atrium fibrillation

A.flut $=$ atrium flutter

Table 1.

Despite the lack of evidence, it is common practice to treat atrial fibrillation in the ICU setting. Many physicians feel the need to restore sinus rhythm in critically ill patients with either electrical cardioversion, chemical conversion or a combination of these treatment strategies. These feelings are predominantly based on their experience in non-critically ill patients. However, critically ill patients differ from the general population, therefore, extrapolating treatment regimes and results are not justified and may even harm. For example, DC electrical cardioversion in patients with new onset atrial fibrillation has a success rate of over $90 \%$, while the only study investigating DC electrical cardioversion in critically ill patients yields an initial success rate of $35 \%$ and only 13,5\% after 48 hours, (Mayr et al 2003) which data are comparable to control group e.g. spontaneous conversion. Guidelines recommend immediate cardioversion in hemodynamic unstable patients. 
Although critically ill patients are often hemodynamic unstable, this is in most cases not directly the results of atrial fibrillation, but on the contrary, atrial fibrillation is often the result of hemodynamic instability. Therefore an approach with direct DC electrical cardioversion may not be suitable in the ICU setting.

Although data are lacking, as mentioned before, most physicians tend to treat atrial fibrillation with rapid ventricular response in some way, therefore, the three cornerstones of treatment for atrial fibrillation include corrections of the underlying condition, rhythm or rate control and prevention of thrombo-embolic complications

\subsection{The underlying condition}

Whether treatment of the underlying condition may restore sinus rhythm or prevent recurrent atrial fibrillation, is not exactly known. However, treatment of the underlying disease and correction of precipitating factors such as electrolyte disturbances, volume imbalance or hypoxia are part of the general treatment in the ICU setting and are treated anyway. By "simply" treating sepsis lots of triggers that may induce atrial fibrillation will be eliminated and in most cases the arrhythmia will convert spontaneously to sinus rhythm by correcting electrolyte disorders and major fluid changes. However, in some of these patients, atrial fibrillation direct contribute to further hemodynamic deterioration of the patient and therefore should be treated as soon as possible. Since, as mentioned before, triggers are available in excess and also cannot always be removed, conversion to sinus rhythm might be a rather optimistic treatment goal, which means, conversion might be possible, but subsequently remaining sinus rhythm might be the Achilles' heel of this treatment strategy. Therefore, a goal that might be easier to achieve might be rate control to an acceptable ventricular frequency.

\subsection{Rhythm or rate control}

Based on the studies performed in the general population, (Van Gelder et al 2002, Wyse et al 2002) and postoperative atrial fibrillation, (Soucier et al 2003) and given the fact that a rhythm strategy with DC electrical cardioversion in critically ill cardiac surgery patients failed to show any benefit (Mayr et al 2003) and furthermore, chemical conversion is often accompanied by severe side effects or is contra-indicated, a rhythm control strategy is not recommend in critically ill patients, with the exception of those patients with life threatening cardiovascular collapse due to atrial fibrillation or in a setting of acute coronary syndrome. In these cases it is recommended to add an anti-arrhythmic drug in order to maintain sinus rhythm.

This might introduce another problem, while most anti-arrhythmic drugs lower pressure or are contra-indicated in ischemic heart failure.

Experience with rather new Vaughan-Williams class III anti arrhythmic drugs like ibutilide or nifekalant for chemical conversion is scarce. Ibitulide has been used in a few studies, (Bernard et al 2003, Hennersdorf et al 2002, Varriale et al 2000) but for the fact of limited safety data, we cannot recommend treatment with ibitulide in the ICU setting.

Few studies in critically ill patients have shown that just lowering ventricular rate by drugs that lower $\mathrm{AV}$ conduction and thereby contributing to more hemodyamic stability is effective for conversion to sinus rhythm. Amiodarone intravenously is the most common used anti-arrrhythmic drug in this setting.

Amiodarone, a type III anti-arrhythmic drug with also class II and IV effects, is well tolerated in hemodynamic unstable patients. Even patients with compromised left ventricular function can be safely treated with amiodarone. (Kumar 1996) However, the 
high rate of serious adverse reactions makes amiodarone very unpopular. These adverse reactions are usually seen in prolonged administration although, amiodarone-induced pulmonary toxicity (Daniels et al 1997, Donaldson et al 1997, Laprinsky et al 1993, Van Mieghem et al 1994) and acute liver failure (Bravo et al 2005) may also present within days or weeks. These short terms adverse reactions of amiodarone are not well studied and may be underdiagnosed in clinical trials, especially in critically ill patients, since these patients often have more than one reason to develop (multi) organ failure.

Beta adrenergic receptor blockers or nondihydropyridine calcium channel blockers like verapamil are also widely used for lowering ventricular rate, however, in ICU setting, these drugs may further compromise hemodynamic state in critically ill patients.

The use of magnesium has shown some promising results both in critically ill patients (Sleeswijk et al 2008, Moran et al 1995) as also in the general population presenting with new onset atrial fibrillation. (Gullenstad et al 1993) However, the anti-arrhythmic effect of magnesium is not completely understood. A normal serum level of magnesium does not rule out an absolute magnesium deficiency since magnesium is mainly located intracellular. So, it is difficult to establish whether the anti-arrhythmic effects of magnesium are mainly due to repletion of intracellular hypomagnesiaor the result of the presumed effect on NaK-ATP-ase (Dyckner 1980, Ebel 1983) or the effect of blocking of calcium channels. (White et al 1989) However, magnesium seems to be effective in patients with both a low and normal level of serum magnesium. (Eray et al 2000) The optimal dosage of magnesium has not yet been establish. There are different regimens used in clinical trials, which may explain the difference in success of the treatment.

The facts that hypomagnesia is frequently seen in critically ill patients (Ryzen et al 1985) and that hypomagnesia is associated with increased mortality (Chernow et al 1989), in combination with the positive effects of magnesium seen on both ventricular and supraventricular arrhythmia, (Toraman et al 2001, Gullenstad et al 1993, Sleeswijk et al 2008, Moran et al 1995, Chiladakis et al 2001, Hays et al 1994, Jensen et al 1997) in the absence of serious adverse effects, and furthermore combined with the low cost, the prophylactic effect on pro-arrhythmia, (Caron et al 2003), the synergistic effect with anti-arrhythmic drugs (Kalus et al 2003) and the reduction for the need of potential toxic anti-arrhythmic, (Sleeswijk et al 2008) justify its use in all critically ill patients with atrial fibrillation. Of course, serum levels should be monitored, especially in those with renal failure, to prevent toxicity of hypermagnesia. Although there are different regimes used in clinical trials, we suggested a treatment regime with a bolus magnesium of 0.037 gram $/ \mathrm{kg}$ body weight within 15 minutes followed by a continuous infusion of $0.025 \mathrm{gram} / \mathrm{kg}$ body weight / hour. (Sleeswijk et al 2008, Moran et al 1995)

Digoxin is one of the oldest anti-arrhythmic drugs with positive inotropic and negative dromotropic effect. However, its dromotropic effect is very disappointing, especially in the critically ill patients probably because the enhanced adrenergic state which is seen in these patients. (Falk et al 1987, Clemo et al 1998, Goldman et al 1975) Furthermore, digoxin has several serious side effects and the combination of rather ineffectiveness with safety matters makes digoxin not recommended in critically ill patients.

Since inflammation plays an important crucial role in the pathophysiology of new onset atrial fibrillation in critically ill patients, it is tempting to use anti-inflammatory agents for the treatment and prevention of atrial fibrillation. Glucocorticoids, (Whitlock et al 2008) statins, angiotensin converting enzyme inhibitor and 3 fatty acids (Guglin et al 2008) may have shown to be effective in preventing or termination atrial fibrillation by modulating the substrate. Due to the limited evidence and safety concerns these agents cannot yet be recommended for the treatment of new onset atrial fibrillation in critically ill patients. 


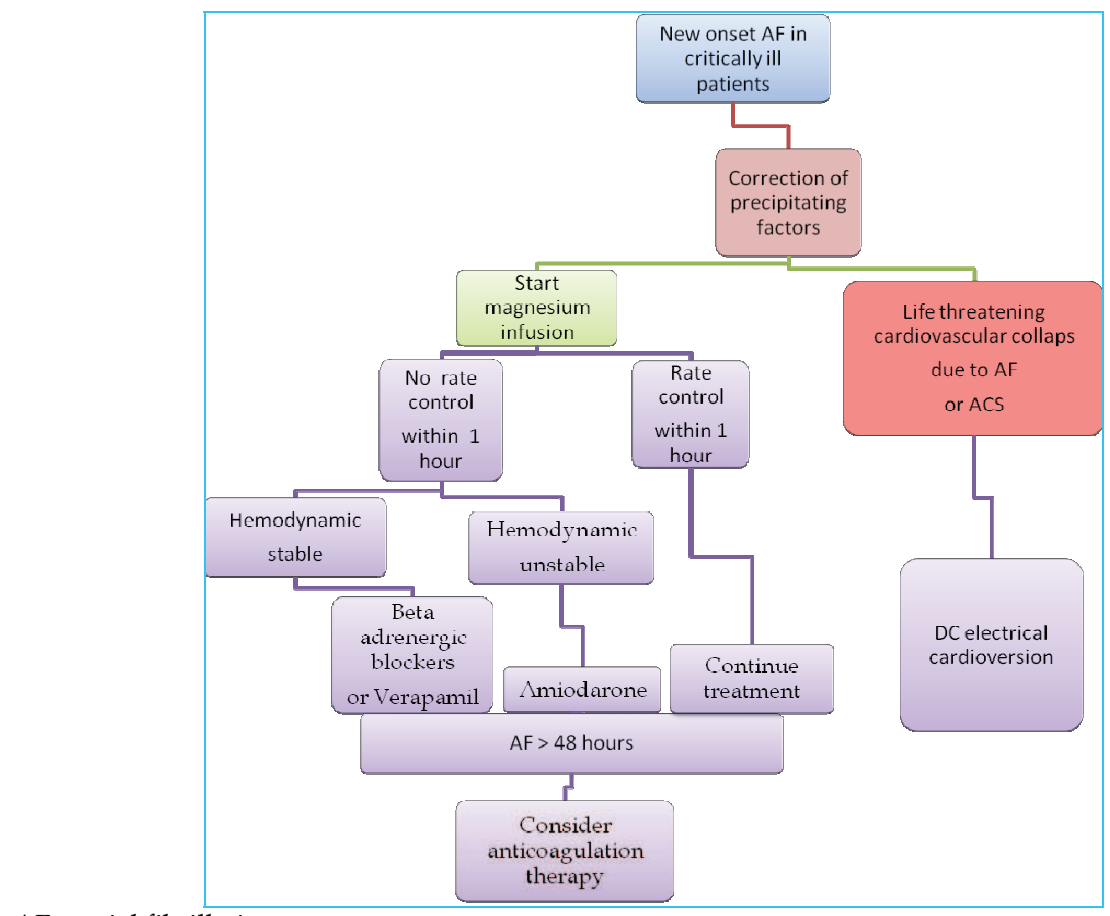

$\mathrm{AF}=$ atrial fibrillation

ACS $=$ acute coronary syndrome

Fig. 1. Treatment algorithm for new onset atrial fibrillation in critically ill patients.

In summarize, the treatment of new onset atrial fibrillation in critically ill patients should start with the correction of precipitating factors and is further primarily aimed at a rate control strategy, starting with the infusion of magnesium. If rate control is not achieved we recommend amiodarone for the unstable patients and in hemodynamic stable patients a beta adrenergic receptor blocker of verapamil can be started. With this regime conversion to sinus rhythm will occur within 24 hours in most patients.

\section{Prevention of thrombo-embolic complications}

The risk for thrombo-embolic complication is increased in patients with atrial fibrillation lasting for more than 48 hours. Critically ill patients are at risk for thrombo-embolic complications due to their underlying disease and immobility. The formation of thrombi in atrial fibrillation is the result of the combination of blood coagulation status, vessel wall related factors and reduced blood flow. All these 3 factors are altered in favor of more easily development of thrombi in critically ill patients. Furthermore, inflammation, usually present in critically ill patients, might enhance development of thrombosis. However, critically ill patients also have a high risk of bleeding complications due to coagulation disorders (Levi et al 2006) or the need for invasive procedures during their stay in the ICU.

In each patient the benefit of stroke prevention must be weighed against the risk of bleeding. Although data are lacking, we tend to mention that the CHADS2 risk calculator for thrombo-embolic complication in atrial fibrillation cannot be applied in the critically ill. 
In case of persistent atrial fibrillation for at least 48 hours, one should consider starting anticoagulant therapy in critically patients. Due to the high bleeding risk we recommend treatment with unfractionated heparin or short acting low molecular weight heparin.

\section{Prognosis}

Treatment with magnesium and or drugs that lower AV node conduction is in most case effective to restore sinus rhythm within 24 hours. Recurrence rate and long term outcome has not been studied in critically ill patients. New onset atrial fibrillation in critically ill patients is associated with increased mortality, morbidity and prolonged ICU stay. (Sleeswijk et al 2007) However, a causal link between atrial fibrillation and mortality has not yet been found. Atrial fibrillation may simply be a marker of severity of illness rather than an independent contributor of mortality.

\section{References}

Balser JR, Martinez EA, Winters BD, et al: Beta-adrenergic blockade accelerates conversion of postoperative supraventricular tachyarrhythmias. Anesthesiology 1998; 89: 10521059

Barranco F, Sanchez M, Rodriguez J, Guerrero M Efficacy of flecainide in patients with supraventricular arrhythmia and respiratory insufficiency. Intensive Care Med. 1994; 20:42-4

Bernard EO, Schmid ER, Schmidlin D, et al: Ibutilide versus amiodarone in atrial fibrillation: A double-blinded, randomized study. Crit Care Med 2003; 31:1031-1034

Bravo AE, Drewe J, Schlienger RG, Krahenbuhl S, Pargger H, Ummenhofer W. Hepatotoxicity during rapid intravenous loading with amiodarone: Description of three cases and review of the literature. Crit Care Med. 2005 Jan; 33(1):128-134

Caron MF, Kluger J, Tsikouris JP, Ritvo A, Kalus JS, White CM Effects of intravenous magnesium sulfate on the QT interval in patients receiving ibutilide.Pharmacotherapy. 2003 Mar; 23(3):296-300

Chapman MJ, Moran JL, O'Fathartaigh MS, et al: Management of atrial tachyarrhythmias in the critically ill: A comparison of intravenous procainamide and amiodarone. Intensive Care Med 1993; 19:48-52

Chernow B, Bamberger S, Stroiko M, et al: Hypomagnesemia in patients in the postoperative intensive care unit. Chest 95:391-397, 1989

Chiladakis JA, Stathopoulos C, Davlouros P, Manolis AS.Intravenous magnesium sulfate versus diltiazem in paroxysmal atrial fibrillation. Int J Cardiol. 2001 Jul; 79(2-3):28791

Christian SA, Schorr C, Ferchau L, Jarbrink ME, Parrillo JE, Gerber DR. Clinical characteristics and outcomes of septic patients with new-onset atrial fibrillation. J Crit Care. 2008 Dec; 23(4):532-6.

Chung MK, Martin DO, Sprecher D, et al: C-reactive protein elevation in patients with atrial arrhythmias: Inflammatory mechanisms and persistence of atrial fibrillation. Circulation 2001; 104:2886-2891

Daniels CJ, Schutte DA, Hammond S, Granklin WH (1997) Acute pulmonary toxicity in an infant from intravenous amiodarone. Am J Cardiol 80:1113-1116

Dernellis J, Panaretou M: C-reactive protein and paroxysmal atrial fibrillation: Evidence of the implication of an inflammatory process in paroxysmal atrial fibrillation. Acta Cardiol 2001; 56:375-380 
Donaldson L, Grant IS, Naysmith MR, Thomas JS (1997) Amiodarone should be used with caution in patients in intensive care (letter). BMJ 314:1832

Dyckner T: Serum magnesium in acute myocardial infarction -Relation to arrhythmias. Acta Med Scand 1980; 207: 59-66

Ebel H: Role of magnesium in cardiac disease. J Clin Chem Clin Biochem 1983; 21: 249-265

Eray O, Akca S, Pekdemir M, Eray E, Cete Y, Oktay C. Magnesium efficacy in magnesium deficient and non deficient patients with rapid ventricular response atrial fibrillation. Eur J Emerg Med. 2000 Dec; 7(4):287-90

Falk RH, Knowlton AA et al. Digoxin for converting recent-onset atrial fibrillation to sinus rhythm: a randomised double-blind trial. Ann Intern Med 1987; 106:503-506

Gaudino M, Andreotti F, Zamparelli R, et al: The -174G/C interleukin-6 polymorphism influences postoperative interleukin-6 levelsand postoperative atrial fibrillation: Is atrial fibrillation an inflammatory complication? Circulation 2003; 108 (Suppl 1):II195-II19

Clemo HF, Wood MA, Gilligan DM, et al: Intravenous amiodarone for acute heart rate control in the critically ill patient with atrial tachyarrhythmias. Am J Cardiol 1998; 81:594-598

Goldman S, Probst P, et al. Inefficacy of therapeutic serum levels of digoxin in controlling the ventricular rate in atrial fibrillation. Am J Cardiol 1975; 35:651655

Guglin M, Garcia M, Yarnoz MJ and Curtis AB. Non-antiarrhythmic medications for atrial fibrillation: From bench to clinical practice. J Interv Card Electrophysiol (2008) 22:119-128

Gullestad L, Birkeland K, Molstad P, Hoyer MM, Vanberg P, Kjekshus J. The effect of magnesium versus verapamil on supraventricular arrhythmias. Clin Cardiol. 1993 May; 16(5):429-34

Hays JV, Gilman JK, Rubal BJ. Effect of magnesium sulfate on ventricular rate control in atrial fibrillation. Ann Emerg Med. 1994 Jul; 24(1):61-4

Hennersdorf M, Stefan M. Perings, Christian Zühlke, Ulrich E. Heidland, Christian Perings Matthias P. Heintzen, Bodo E. Strauer, Conversion of recent-onset atrial fibrillation or flutter with ibutilide, after amiodarone has failed Intensive Care Med (2002) 28:925-929

Holt AW: Hemodynamic responses to amiodarone in critically ill patients receiving catecholamine infusions. Crit Care Med 1989; 17:1270-1276

Jensen BM, Alstrup P, Klitgard NA. Magnesium substitution and postoperative arrhythmias in patients undergoing coronary artery bypass grafting Scand Cardiovasc J. 1997; 31(5):265-9

Kalus JS, Spencer AP, Tsikouris JP, Chung JO, Kenyon KW, Ziska M, Kluger J, White CM. Impact of prophylactic i.v. magnesium on the efficacy of ibutilide for conversion of atrial fibrillation or flutter.Am J Health Syst Pharm. 2003 Nov 15;60(22):2308-12

Kumar A. Intravenous amiodarone for therapy of atrial fibrillation and flutter in critically ill patients with severely depressed left ventricular function. South Med J. 1996 Aug;89(8):779-85.

Laprinsky SE, Mullen JB, Baller MS (1993) Rapid pulmonary phospholipid accumulation induced by intravenous amiodarone. Can J Cardiol 9:322-324

Levi M and Opal SM. Coagulation abnormalities in critically ill patients. Crit Care 2006; 10(4):222

Mayr A, Ritsch N, Knotzer $\mathrm{H}$, et al: Effectiveness of direct-current cardioversion for treatment of supraventricular tachyarrhythmias, in particular atrial fibrillation, in surgical intensive care patients. Crit Care Med 2003; 31:401-405 
Meierhenrich R, Steinhilber E, Eggermann C, Weiss M, Voglic S, Bögelein D, Gauss A, Georgieff M, Stahl W

Incidence and prognostic impact of new-onset atrial fibrillation in patients with septic shock: a prospective observational study. Crit Care. 2010; 14(3):R108. Epub 2010 Jun 10.

Moran JL, Gallagher J, Peake SL, et al: Parenteral magnesium sulfate versus amiodarone in the therapy of atrial tachyarrhythmias:A prospective, randomized study. CritCare Med 1995; 23:1816-1824

Ryzen E, Wagers PW, Singer FR, et al: Magnesium deficiency in a medical ICU population. Crit Care Med 13:19-21, 1985

Salman S, Bajwa A, Gajic O, Afessa B. Paroxysmal atrial fibrillation in critically ill patients with sepsis. J int care med. 2008:23(3):178-183

Seguin P, Laviolle B, Maurice A, Leclercq C, Mallédant Y. Atrial fibrillation in trauma patients requiring intensive care. Intensive Care Med. 2006 Mar; 32(3):398-404. Epub 2006 Jan 27

Sleeswijk ME, Tulleken JE, Noord van T, Meertens JHJM, Ligtenberg JJM and Zijlstra JG. Efficacy of Magnesium-Amiodarone Step-Up Scheme in Critically Ill Patients with new-onset atrial fibrillation: A Prospective Observational Study. J Int Care Med 2008; 23; 61-66

Sleeswijk ME, Noord van T, Tulleken JE, Ligtenberg JJM, Girbes ARJ and Zijlstra JG. Clinical review: Treatment of new-onset atrial fibrillation in medical intensive care patients - a clinical framework. Critical Care 2007, 11:233;

Soucier R, Silverman D, Abordo M, Jaagosild P, Abiose A, Madhusoodanan KP, Therrien M, Lippman N, Dalamagas H, Berns E. Propafenone versus ibutilide for post operative atrial fibrillation following cardiac surgery: neither strategy improves outcomes compared to rate control alone (the PIPAF study). Med Sci Monit. 2003 Mar; 9(3):PI19-23

Toraman F, Karabulut EH, Alhan HC, Dagdelen S, Tarcan S.Magnesium infusion dramatically decreases the incidence of atrial fibrillation after coronary artery bypass grafting. Ann Thorac Surg. 2001 Oct;72(4):1256-61; discussion 1261-2

Van Gelder IC, Hagens VE, Bosker HA, Kingma JH, Kamp O, Kingma T,et al. Rate Control versus Electrical Cardioversion for Persistent Atrial Fibrillation (RACE) Study Group. N Engl J Med 2002; 347:1834-40.

Van Mieghem W, Coolen L, Malysse I, Lacquet LM, Deneffe GJD, Demedts MGP (1994) Amiodarone and the development of ARDS after lung surgery. Chest 105:1642-1645

Varriale P, Sedighi A: Acute management of atrial fibrillation and atrial flutter in the critical care unit: Should it be ibutilide? Clin Cardiol 2000; 23:265-268

White RE, Hartzell HC: Magnesium ions in cardiac function. Regulator of ion channels and second messengers. Biochem Pharmacol 1989; 38: 859-867

Whitlock RP, Chan S, Devereaux PJ, Sun J, Rubens FD, Thorlund K, Teoh KH. Clinical benefit of steroid use in patients undergoing cardiopulmonary bypass: a metaanalysis of randomized trials. Eur Heart J. 2008 Nov; 29(21):2592-600. Epub 2008 Jul 28.

Wyse DG, Waldo AL, DiMarco JP, Domanski MJ, Rosenberg Y, Schron EB, et al. The Atrial Fibrillation Follow-up Investigation of Rhythm Management (AFFIRM) Investigators. A comparison of rate control and rhythm control in patients with atrial fibrillation. N Engl J Med 2002; 347:1825-33. 


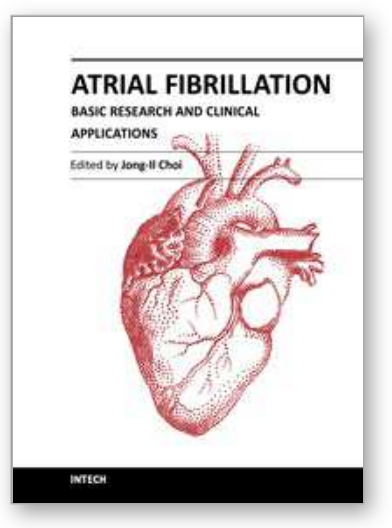

\author{
Atrial Fibrillation - Basic Research and Clinical Applications \\ Edited by Prof. Jong-II Choi
}

ISBN 978-953-307-399-6

Hard cover, 414 pages

Publisher InTech

Published online 11, January, 2012

Published in print edition January, 2012

Atrial Fibrillation-Basic Research and Clinical Applications is designed to provide a comprehensive review and to introduce outstanding and novel researches. This book contains 22 polished chapters and consists of five sections: 1. Basic mechanisms of initiation and maintenance of atrial fibrillation and its pathophysiology, 2 . Mapping of atrial fibrillation and novel methods of signal detection. 3. Clinical prognostic predictors of atrial fibrillation and remodeling, 4. Systemic reviews of catheter-based/surgical treatment and novel targets for treatment of atrial fibrillation and 5. Atrial fibrillation in specific conditions and its complications. Each chapter updates the knowledge of atrial fibrillation, providing state-of-the art for not only scientists and clinicians who are interested in electrophysiology, but also general cardiologists.

\title{
How to reference
}

In order to correctly reference this scholarly work, feel free to copy and paste the following:

M. E. Sleeswijk, T. van Noord and J. G. Zijlstra (2012). New Onset Atrial Fibrillation in Critically III Patients, Atrial Fibrillation - Basic Research and Clinical Applications, Prof. Jong-II Choi (Ed.), ISBN: 978-953-307-399-6, InTech, Available from: http://www.intechopen.com/books/atrial-fibrillation-basic-research-and-clinicalapplications/new-onset-atrial-fibrillation-in-critically-ill-patients

\section{INTECH}

open science | open minds

\section{InTech Europe}

University Campus STeP Ri

Slavka Krautzeka 83/A

51000 Rijeka, Croatia

Phone: +385 (51) 770447

Fax: +385 (51) 686166

www.intechopen.com

\section{InTech China}

Unit 405, Office Block, Hotel Equatorial Shanghai

No.65, Yan An Road (West), Shanghai, 200040, China

中国上海市延安西路65号上海国际贵都大饭店办公楼405单元

Phone: +86-21-62489820

Fax: +86-21-62489821 
(C) 2012 The Author(s). Licensee IntechOpen. This is an open access article distributed under the terms of the Creative Commons Attribution 3.0 License, which permits unrestricted use, distribution, and reproduction in any medium, provided the original work is properly cited. 